\title{
Fatores favorecedores e comprometedores na qualidade acadêmica do ensino de Odontologia
}

\author{
Patricia Figueiredo Medina ${ }^{1}$ \\ Teresa Olinda Caminha Bezerra ${ }^{2}$ \\ Cresus Vinicius Depes de Gouvêa ${ }^{3}$
}

\begin{abstract}
RESUMO
O estudo objetivou identificar os fatores favorecedores e os comprometedores da qualidade do ensino do curso de graduação em Odontologia da Universidade Federal Fluminense. Trata-se de uma pesquisa exploratória realizada em duas etapas distintas, porém com enfoque integrado. As percepções dos professores e dos alunos foram coletadas por meio de questionários. Para a análise dos dados utilizou-se a Análise de Conteúdo, a estatística descritiva e inferencial. Verificou-se que, na visão acadêmica dos segmentos estudados, o principal fator favorecedor foi qualidade do corpo docente e comprometimento. Já em relação aos comprometedores foram apontados como principais: falta de componentes tais como: competência, motivação, assiduidade, comprometimento e comportamento democrático, por parte de alguns professores; falta de integração e interdisciplinaridade entre as disciplinas; programas curriculares tradicionais, antigos e deficientes.
\end{abstract}

PALAVRAS-CHAVE: Ensino de Odontologia. Qualidade do ensino. Diretrizes Curriculares. Fatores favorecedores e comprometedores.

Factors that favor and factors that compromise the academic excellence in dentistry teaching

\footnotetext{
${ }^{1}$ Doutora em Educação pela Universidad de La Empresa - UDE, Montevidéu, Uruguai. Universidade Federal Fluminense, Niterói, Rio de Janeiro, Brasil.. E-mail: patfmedina@gmail.com

${ }^{2}$ Doutora em Educação pela Universidad de La Empresa - UDE, Montevidéu, Uruguai. Universidade Federal Fluminense, Niterói, Rio de Janeiro, Brasil..E-mail: teresa.caminha@gmail.com

${ }^{3}$ Professor Titular Doutor em Odontologia. Universidade Federal Fluminense, Niterói, Rio de Janeiro, Brasil. E-mail: cresusuff@gmail.com
} 


\begin{abstract}
The study aimed to identify the factors that may favor or compromise teaching quality of the dentistry graduation course at Universidade Federal Fluminense (UFF). This is an exploratory research carried out in two distinct phases, but with an integrated approach. The perceptions of teachers and students were collected through questionnaires. Content Analysis as well as descriptive and inferential statistics used for the data analysis. The academic view of the studied segments shows that the main favorable factor was quality of the teaching staff and commitment. Regarding the compromisers, the following were pointed out as main: some of the teacher's lack of components such as competence, motivation, attendance, commitment and democratic behavior; lack of integration programs, lack of interdisciplinary approach; traditional, old and disabled curriculum.
\end{abstract}

KEYWORDS: Dentistry Graduation. Quality of education. Curricular Guidelines; Favoring and compromising factors.

$$
* * *
$$

Ninguém ignora tudo. Ninguém sabe tudo. Todos nós sabemos alguma coisa. Todos nós ignoramos alguma coisa. Por isso aprendemos sempre.

(Paulo Freire, 1989)

\title{
Introdução
}

O Brasil não tem tradição em avaliar o seu sistema educacional. Com a regulamentação da Lei de Diretrizes e Bases da Educação Nacional (LDB n 9394 de dezembro de 1996), a avaliação educacional ganha maior notoriedade, sendo desenvolvidas no país algumas propostas para avaliar a educação superior, como por exemplo, o Programa de Avaliação Institucional das Universidades Brasileiras (PAIUB), que concebe a autoavaliação como etapa inicial de um processo que seria complementado com a avaliação externa (MATOS; TENÓRIO, 2009).

A ideia de qualidade no ensino superior passa a ser amplamente discutida no início dos anos 90, e associadas aos processos avaliativos (SECCO; PEREIRA, 2004). 
Em Bertolin e Marchi (2009, p. 33), as experiências de avaliação que contenham sistemas de indicadores recomendados por organismos internacionais, bem como "as publicações científicas que vinculam avaliação com sistemas de indicadores consideram que a qualidade em educação é um conceito múltiplo que não pode ser avaliado por apenas um indicador", devendo envolver todos os elementos essenciais de um sistema ou processo.

$\mathrm{Na}$ prospecção teórica sobre o ensino de Odontologia e sua qualidade, são identificas literaturas tanto de largo espectro argumentativo quanto específico no processo educacional. Perez Lindo (1998), Masetto (2003) e Libâneo (2004), apontam para a defasagem entre os novos contextos e o ensino. Por isso, as universidades são chamadas a cumprir um duplo papel na sociedade, identificando claramente as demandas de formação emergentes, cuja satisfação contribua de maneira direta à sociedade, ao mesmo tempo, em que assumem um papel de agente sociocultural, antecipando-se às mudanças sociais e gerando conhecimento na realização integral do ser humano por meio de seus cursos acadêmicos e serviços de pesquisa e extensão.

No Brasil, as reflexões desenvolvidas acerca da qualidade do ensino e da formação do cirurgião-dentista levaram o Conselho Nacional de Educação (CNE) através da Câmara de Educação Superior (CES) a instituir as Diretrizes Curriculares Nacionais do Curso de Graduação de Odontologia (DCN) com a Resolução CNE/CES 3 de 19 de fevereiro de 2002 (BRASIL, 2002). A partir daí, essas passam a orientar o planejamento dos cursos de graduação em Odontologia estabelecendo uma base comum para todas as instituições de ensino superior (IES), sejam públicas ou privadas. As diretrizes definem o perfil do cirurgião-dentista e estabelecem as competências e habilidades necessárias para o exercício da profissão. Ainda determinam os princípios, fundamentos, condições e procedimentos para a formação profissional.

O CNE também explicita que o objetivo das Diretrizes dos Cursos de Graduação em Saúde é: 
levar os alunos dos cursos de graduação em saúde a aprender $\boldsymbol{a}$ aprender que engloba aprender a ser, aprender a fazer, aprender a viver juntos a aprender a conhecer, garantindo a capacitação de profissionais com autonomia e discernimento para assegurar a integralidade da atenção e a qualidade e humanização do atendimento prestado aos indivíduos, famílias e comunidades (BRASIL, 2001, p. 4).

Percebe-se que o objetivo acompanha a orientação contida no Relatório sobre Educação para o século XXI, elaborado para a UNESCO (DELORS et al., 1996), no que diz respeito aos quatro pilares da Educação indicados visando enfrentar as mudanças que se aproximam com a nova ordem social.

Dessa maneira, espera-se que os sistemas educativos e a educação superior em saúde contribuiam para a formação de pessoas equilibradas, competentes, reflexivas, críticas, criativas, tolerante às diferenças, humanistas, éticas, socialmente integradas, que dirijam sua atuação para a transformação da realidade em prol da sociedade.

$\mathrm{Na}$ concepção de Feuerwerker (2003), as propostas de mudança na formação dos profissionais de Saúde, provenientes das novas DCN e apoiadas pelo Ministério da Saúde, se voltam à superação de alguns problemas. Dentre esses, a formação "de profissionais críticos, capazes de aprender a aprender, de trabalhar em equipe, de levar em conta a realidade social para prestar atenção humana e de qualidade" (FEUERWERKER, 2003, p. 25), visando transformar o modelo de atenção, melhorar a promoção e prevenção, oferecer atenção integral e fortalecer a autonomia dos sujeitos na produção da saúde.

Para Fischer (2009), nos dias atuais, é imprescindível que os professores reflitam com seus pares e, também, com os alunos, adotando uma orientação pedagógica em que o docente provoque questionamentos concretos encontrados na vida e no campo de ação do futuro profissional. 
Foresti (2001), destaca que a mudança de paradigma da Educação atual precisa contar com a ação concreta dos seus docentes no sentido de promover transformações na estrutura da prática, desconstruindo a lógica da reprodução e memorização, da fragmentação do conhecimento, da disjunção teoria-prática, reconstruindo uma metodologia que atenda as relações entre ciência-construção do conhecimento, ensino-pesquisa, conteúdo-forma, teoria-prática e dimensões pedagógico-epistemológica e política da prática docente na universidade.

A mudança de um paradigma de ensino que tem como foco a especialidade, historicamente fragmentado, para outro focado na integralidade do ser humano, que reflita a realidade epidemiológica do Brasil, de acordo com as exigências do Sistema Único de Saúde (SUS), requisita uma análise profunda, uma vez que são inúmeras as variáveis que fazem parte do contexto de mudança no ensino superior e mais especialmente ao da área de saúde (MORITA et al., 2007; MORAES, 2012).

Entre os aspectos que dificultam a adequação dos cursos de Odontologia às DCN temos como exemplo, em Cordioli (2006), a falta de articulação da teoria com a prática e o pouco preparo para o relacionamento com o paciente. Já Haddad et al. (2006) pontua, entre outros, a dificuldade de integração e modificação curricular; e, a dificuldade em desenvolver projetos pedagógicos inovadores e diferentes do modelo tradicional de ensino. Para os autores, um dos fatores que inibem a concepção curricular para estruturas integradas pode ser atribuído à predominância de um corpo docente com uma formação de caráter especialista.

Para Zilbovicius (2007), nas IES ocorreram poucas inovações na orientação teórica do curso, na abordagem pedagógica e nos cenários de práticas, predominando um enfoque pedagógico tecnicista, sem integração entre disciplinas e com poucos cenários de prática que permitem ao aluno conhecer e se formar na lógica orientada e exigida pelo SUS.

Com a consolidação do SUS e sobretudo com a expansão do Programa Saúde da Família, muito importante para a área de saúde bucal, é quase 
imperioso que as IES repensem os seus currículos, visando a formação de profissionais que estejam aptos a atender aos imperativos "socioeconômicas do país, melhorando, assim, os índices de saúde. Para isso, a construção do projeto pedagógico deve se voltar aos problemas advindos das interações que se estabelecem entre as IES, os governos e a sociedade" (LAZZARIN; NAKAMA; JÚNIOR, 2007, p. 98).

Para Bezerra (2011, p. 18) o professor precisa estar voltado a buscar o seu verdadeiro papel na formação das gerações futuras, estendendo sua ação, "na perspectiva dos desafios e dificuldades que assolam nosso País, no que se refere às desigualdades econômicas, sociais e culturais, ao invés de voltar-se unicamente ao conteúdo programático da disciplina”.

Finkler (2009), ao investigar a formação ética na graduação em Odontologia em sua tese de doutorado, confirma a hipótese inicial de que a dimensão ética da formação profissional em Odontologia, nos cursos brasileiros de graduação, precisa ser mais bem desenvolvida para o pleno exercício da excelência profissional, opinião compactuada também por Matos; Tenório (2009) e Moraes (2012).

Outros autores entendem que a formação e a competência pedagógica do professor são fatores que contribuem para o quadro insatisfatório do ensino odontológico vigente (REIS et al., 2009; MASETTO, 2003; PIMENTA; ANASTASIOU; CAVALLET, 2003). Concebem que, geralmente, os docentes que atuam nas universidades, são aqueles que cursaram apenas uma disciplina de metodologia do ensino superior. Segundo Antunes (2004), para enfrentar os desafios dessa nova Educação, os docentes deveriam dominar oito competências, entre elas temos: sentir entusiasmo pelo que ensinam provocando no aluno o desejo de aprender; esclarecer a relação entre a aprendizagem e o saber; organizar as etapas que se busca desenvolver; administrar sua formação contínua e permanente; desenvolver a consciência de sua profissão e o sentido de responsabilidade, solidariedade e justiça.

Na percepção de Secco e Pereira (2004) a formação didático-pedagógica do professor de Odontologia, quase nada questionada até pouco tempo atrás, 
ganha espaço no debate acadêmico, desde o aparecimento de novas necessidades sociais advindas dos processos de globalização e informatização do mundo moderno. Tanto os diversos câmbios no cenário social, quanto as novas orientações anunciadas pelas DCN trazem demandas por pesquisas e estudos direcionados à qualidade da Educação superior exigindo "uma postura crítica em relação à concepção de qualidade em educação, considerando que um dos desafios nos países latino-americanos ainda é garantir a cidadania" (SECCO; PEREIRA, 2004, p. 314).

Estes aspectos evidenciam a problemática da defasagem existente entre a qualidade atual dos cursos de graduação em Odontologia e os desafios necessários à sua adequação ao atendimento das DCN. Neste cenário, sobre os caminhos a tomar em busca de qualidade, este estudo objetiva identificar fatores favorecedores e comprometedores da qualidade do ensino no curso de graduação em Odontologia da Universidade Federal Fluminense (UFF). Espera-se, assim, democratizar informações e saberes e facilitar o crescimento institucional.

\section{Metodologia}

Trata-se de uma pesquisa exploratória, resultante da tese de doutorado de Medina (2014), que assumiu um modelo de duas etapas com enfoque integrado (MALHOTRA, 2004; SAMPIERI; COLLADO; LUCIO, 2006). Na primeira etapa, foi realizada uma abordagem qualitativa, que serviu de base para uma segunda, de natureza quantitativa.

No que diz respeito à população-alvo do estudo, optou-se por trabalhar com alunos e professores do curso de graduação em Odontologia de uma universidade pública do Estado do Rio de Janeiro, Brasil. Ressalta-se que o estudo obteve a autorização do Diretor da referida unidade para a realização da pesquisa na instituição e aos participantes foram dadas as informações a respeito da finalidade da pesquisa e dos seus principais aspectos metodológicos. A partir da concordância dos mesmos a participação foi efetivada. 
$\mathrm{Na}$ primeira etapa, a seleção da amostra foi intencional, ou seja, por informantes-chave. Estabeleceu-se como critério de inclusão para a seleção dos informantes-chave: alunos representantes de turma do $3^{\circ}$ ao $9^{\circ}$ período, gestores (diretor, coordenador de curso, chefes de departamento, presidente do diretório acadêmico), professores coordenadores de disciplinas com mais de cinco anos de magistério, por haver confiança na obtenção da qualidade dos dados dos mesmos. Como critérios de exclusão adotaram-se: representantes de turma do $1^{\circ}$ e $2^{\circ}$ períodos e professores com experiência menor que 5 anos.

O instrumento utilizado para coleta de dados foi um questionário formulado para a pesquisa com questões abertas após pré-teste, no qual se solicitou aos informantes-chave que indicassem fatores, existentes na universidade, que lhes parecessem comprometer ou favorecer a qualidade do ensino de graduação em Odontologia.

Os dados foram analisados continuamente por Análise de Conteúdo Categorial (BARDIN, 1977). A técnica de saturação de conteúdo foi utilizada para interromper esta fase junto às possíveis pessoas-chave. Desta maneira, esta etapa contou com a participação de 7 alunos representantes de turma, 1 aluno gestor, 4 professores gestores e 8 professores coordenadores de disciplina, segundo os critérios estabelecidos antes, perfazendo uma amostra de 20 informantes-chave.

$\mathrm{Na}$ fase de tratamento dos resultados obtidos e interpretação confeccionaram-se quadros sínteses acerca dos fatores favorecedores e dos fatores comprometedores com a listagem das categorias e suas respectivas frequências para a amostra. O critério utilizado para o quadro foi a escolha das categorias comuns aos dois grupos e, de forma a completar 10 fatores, entraram os com maior frequência em qualquer dos grupos.

Os resultados obtidos da análise propiciaram toda uma elaboração teórica que alimentou a construção do questionário para a fase quantitativa, bem como, a discussão dos resultados da pesquisa. 
A segunda etapa contou com a participação efetiva de 385 respondentes (293 alunos e 92 professores) do universo composto de 490 sujeitos (374 alunos e 116 professores), o que representa em percentual 78\% dos alunos e $79 \%$ dos professores.

O segundo instrumento foi um questionário formulado com questões fechadas a partir das respostas dadas pelos informantes-chave no questionário inicial. As questões foram elaboradas de modo que, cada uma apresentou uma escala de ordenação de pontos (MALHOTRA, 2004), com o propósito de conhecer a ordem de importância dos fatores. A primeira questão tinha a recomendação que se segue: em ordem de prioridade de $1 \mathrm{a}$ 10, atribua o valor 1 ao fator que você considera como sendo o mais favorecedor da qualidade do ensino na universidade pesquisada. A seguir, dê o valor 10 ao que menos tem favorecido a qualidade do ensino de Odontologia, na mesma instituição e, posteriormente, valores intermediários. Por favor, dê um valor diferente a cada fator, ou seja, não repita o mesmo valor para mais de um fator. A segunda questão com recomendação similar foi elaborada para os fatores comprometedores.

Para análise dos dados, as respostas dos participantes foram tabuladas por grupos de alunos e de professores, conforme a ocorrência de classificação por questionários. Após a tabulação, obtiveram-se as frequências em cada classificação para cada um dos fatores da questão. A seguir foi atribuída, de modo arbitrário, uma pontuação contrária à classificação. Os dados foram tabulados com essas pontuações para obtenção de um total geral de pontos (MATTAR, 2005). Ainda, foi calculada a pontuação média dos pontos acumulados para cada fator. Assim, dos resultados da ordem de importância apresentados, a classificação 1 significou o mais importante e 10 o menos importante.

Os resultados obtidos da análise das escalas de ordenação de pontos dos fatores, também foram submetidos à análise estatística descritiva e inferencial na população a partir das amostras, verificando-se as possíveis diferenças estatísticas entre cada um dos fatores favorecedores ou 
comprometedores com os demais fatores favorecedores e comprometedores, respectivamente, em cada grupo pesquisado.

O aplicativo Excel da Microsoft foi utilizado para a obtenção das descrições estatísticas, para os cálculos dos intervalos de confiança e para a realização dos testes de hipóteses que envolveram a estatística t de Student. Foram consideradas estatisticamente significativas as diferenças entre médias de pontuação de fatores para as quais o valor-p não tenha superado o nível de significância $\alpha=0,05$ (5\%).

A interpretação dos resultados foi analisada a partir dos aportes teóricos sobre a qualidade do ensino e das DCN.

\section{Resultados e discussão}

Os resultados da etapa qualitativa estão descritos nos quadros 1 e 2 de acordo com as questões dos questionários.

Quadro 1: Síntese dos fatores favorecedores

\begin{tabular}{|l|c|c|c|}
\hline \multicolumn{1}{|c|}{ FATORES FAVORECEDORES } & \multicolumn{3}{c|}{ Frequência } \\
\cline { 2 - 5 } & Aluno & Professor & TOTAL \\
\hline $\begin{array}{l}\text { Qualidade do corpo docente e } \\
\text { comprometimento }\end{array}$ & 6 & 13 & 19 \\
\hline $\begin{array}{l}\text { Infraestrutura adequada (prédio, clínicas, } \\
\text { materiais, equipamentos e instalaços) }\end{array}$ & 7 & 7 & 14 \\
\hline Qualidade do corpo discente & 2 & 5 & 7 \\
\hline $\begin{array}{l}\text { Programa curricular flexível (carga horária } \\
\text { adequada, organização e autonomia relativa } \\
\text { das disciplinas, carga horária para estágio) }\end{array}$ & 1 & 6 & 7 \\
\hline $\begin{array}{l}\text { Programas associados a } \\
\text { ensino/pesquisa/ciência e tecnologia }\end{array}$ & 2 & 3 & 5 \\
\hline Acervo da biblioteca de boa qualidade & 2 & 2 & 4 \\
\hline Equipes qualificadas (funcionários e técnicos) & 1 & 3 & 4 \\
\hline $\begin{array}{l}\text { Qualidade no relacionamento - } \\
\text { professor/aluno, aluno/aluno }\end{array}$ & 1 & 2 & 3 \\
\hline Incentivo à pesquisa & 1 & 2 & 3 \\
\hline $\begin{array}{l}\text { Qualidade do conteúdo teórico de algumas } \\
\text { disciplinas }\end{array}$ & 2 & 0 & 2 \\
\hline
\end{tabular}

Fonte: Adaptado de Medina (2014). 
Quadro 2: Síntese dos fatores comprometedores

\begin{tabular}{|l|c|c|c|}
\hline \multicolumn{1}{|c|}{ FATORES COMPROMETEDORES } & \multicolumn{2}{c|}{ Frequência } \\
\cline { 2 - 4 } & Aluno & Professor & TOTAL \\
\hline $\begin{array}{l}\text { Programas curriculares tradicionais, antigos } \\
\text { e deficientes }\end{array}$ & 9 & 12 & 21 \\
\hline $\begin{array}{l}\text { Falta de integração e interdisciplinaridade } \\
\text { entre as disciplinas }\end{array}$ & 3 & 11 & 14 \\
\hline $\begin{array}{l}\text { Falta de componentes tais como: competência, } \\
\text { motivação, assiduidade, comprometimento e } \\
\text { comportamento democrático, por parte de } \\
\text { alguns professores }\end{array}$ & 5 & 8 & 13 \\
\hline $\begin{array}{l}\text { Infraestrutura (prédio, equipamentos, } \\
\text { instalações, entre outros) insatisfatória para } \\
\text { as atividades práticas e as de pesquisa }\end{array}$ & 5 & 4 & 9 \\
\hline $\begin{array}{l}\text { Acervo bibliotecário insuficiente e } \\
\text { ultrapassado }\end{array}$ & 4 & 2 & 6 \\
\hline $\begin{array}{l}\text { Ausência de prontuário único dos pacientes } \\
\text { assistidos nas clínicas }\end{array}$ & 1 & 3 & 4 \\
\hline $\begin{array}{l}\text { Falta de esclarecimento dos critérios de } \\
\text { avaliação utilizados por alguns professores }\end{array}$ & 2 & 2 & 4 \\
\hline $\begin{array}{l}\text { Falta de programa de acolhimento, triagem e } \\
\text { de cunho emergencial para pacientes }\end{array}$ & 0 & 3 & 3 \\
\hline $\begin{array}{l}\text { Alunos pouco comprometidos, muito jovens e } \\
\text { com formação insatisfatória anterior à } \\
\text { Universidade }\end{array}$ & 0 & 2 & 2 \\
\hline $\begin{array}{l}\text { Formação muito especializada de alguns } \\
\text { docentes }\end{array}$ & 0 & 2 & 2 \\
\hline
\end{tabular}

Fonte: Adaptado de Medina (2014).

A análise dos resultados dos fatores pesquisados entre os grupos revela que alunos e professores apresentam a mesma preocupação em relação a sete dos dez fatores comprometedores que compõem o quadro 2. As diferenças recaem em três dos mesmos: "falta de programa de acolhimento, triagem e de cunho emergencial para pacientes"; "alunos pouco comprometidos, muito jovens e com formação insatisfatória anterior à Universidade"; e, "formação muito especializada de alguns docentes"; que foram mencionados apenas pelos docentes. No que se refere aos fatores favorecedores do quadro 1, o número de coincidências é ainda maior, tem-se nove em dez fatores. Apenas um citado pelos alunos, difere: "qualidade do conteúdo teórico de algumas disciplinas". Da análise dessas poucas diferenças, pode-se observar que alunos e professores pensam de forma muito semelhante em relação a que fatores comprometem e favorecem a 
qualidade do ensino de graduação em Odontologia da universidade pesquisada. Por outro lado, a comparação entre o teor dos fatores favorecedores e comprometedores apontados pela pesquisa demonstra existir uma contradição moderada, indicando que a universidade, em seu curso de graduação em Odontologia não apresenta uma única leitura em relação aos fatores que influenciam a qualidade do referido ensino.

Da etapa quantitativa, os resultados da ordem de importância atribuída aos fatores favorecedores e comprometedores pelos dois grupos pesquisados estão caracterizados nos Gráficos 1 e 2 , sendo 1 , o mais importante, e 10 o menos importante.

Gráfico 1: Comparação da ordem da importância dos fatores favorecedores entre professores e alunos, listados segundo a ordem que constou do questionário de pesquisa

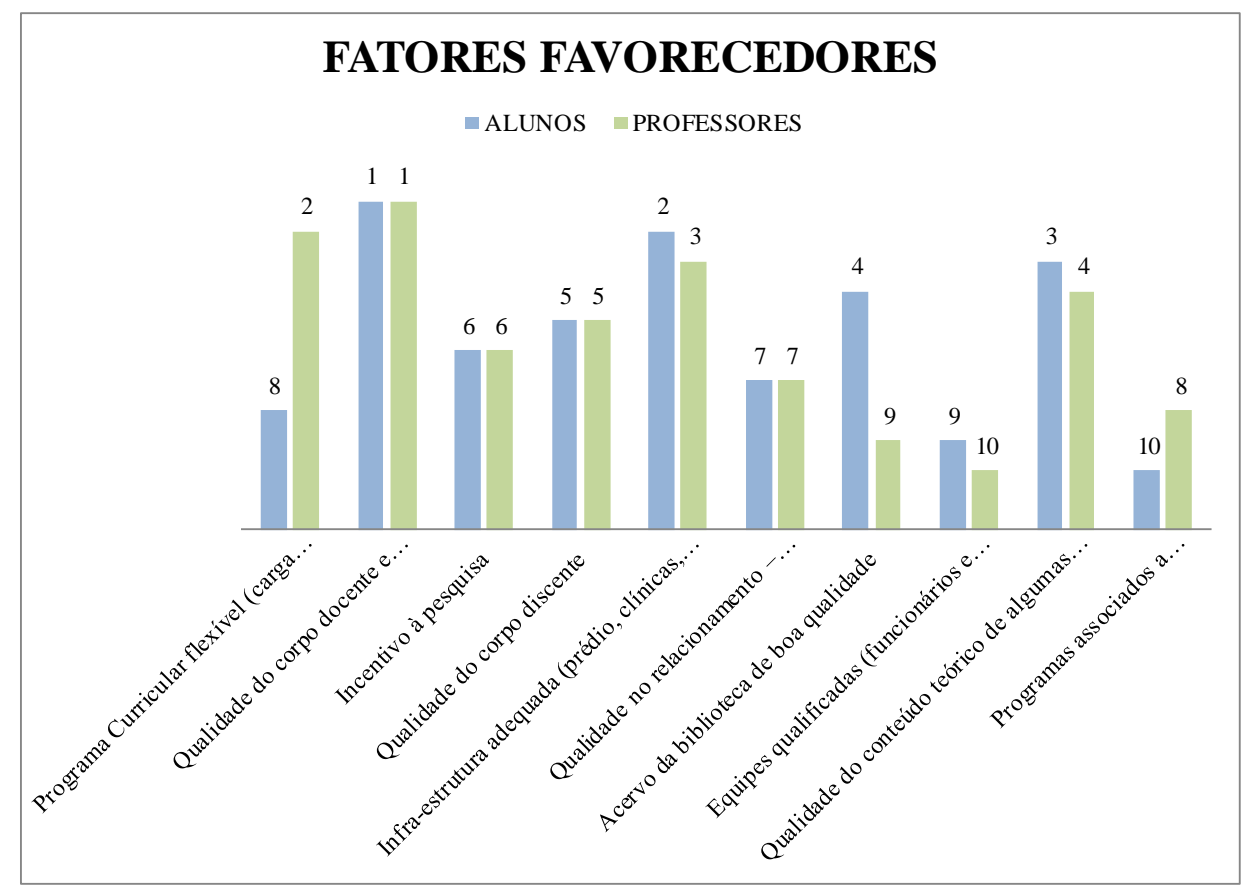

Fonte: Medina (2014). 
Gráfico 2: Comparação da ordem da importância dos fatores comprometedores entre professores e alunos, listados segundo a ordem que constou do questionário de pesquisa

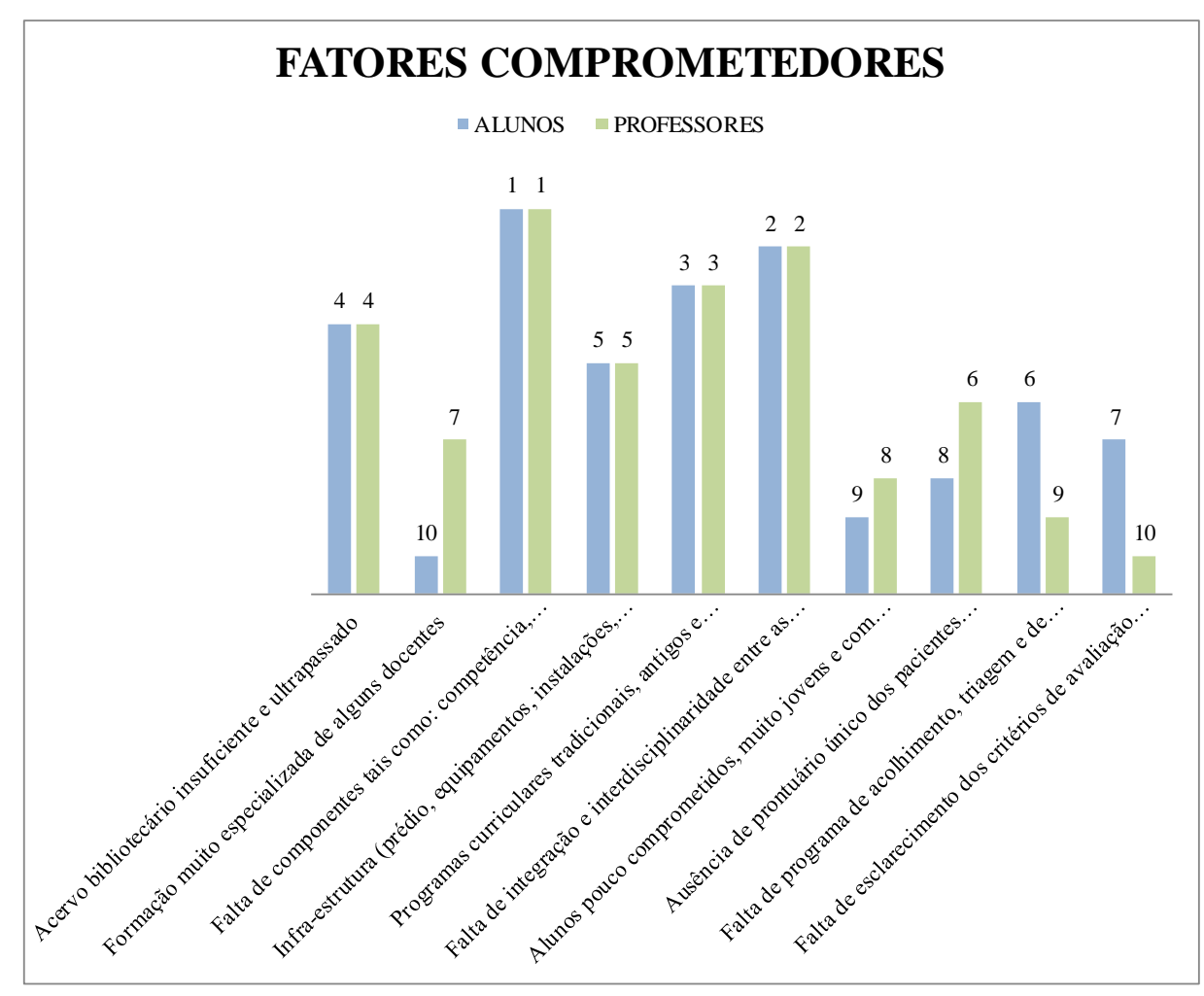

Fonte: Medina (2014).

A avaliação dos fatores favorecedores realizada pelos professores os classificou em ordem de importância segundo o total de pontos na amostra dos que responderam à convocação da pesquisa. $\mathrm{O}$ fator favorecedor mais importante, segundo eles, foi o fator "qualidade do corpo docente e comprometimento" (Gráfico 1), que obteve a pontuação média de 8,5. A importância dada a ele pelo grupo dos professores mostrou-se diferenciada, com significância estatística $(p<0,05)$ das pontuações médias de todos os outros nove fatores favorecedores indicados na pesquisa.

A inferência dessa importância para a totalidade dos professores através do intervalo de confiança permite concluir que a pontuação média populacional desse fator, com $95 \%$ de confiança, se situa entre 8,26 e 8,76.

O caso desse fator se destacar de todos os demais em importância é confirmado pela avaliação da Figura 1, na qual se pode verificar que o seu 
intervalo de confiança se encontra mais à direita na escala de pontuação e não apresenta qualquer interseção com os intervalos de confiança dos demais fatores. Percebe-se na análise da Figura 1 que todos os outros fatores se aglutinam de modo que, em termos da população de professores, eles formam um bloco de fatores menos importantes do que o do primeiro lugar, sem muita distinção global entre eles, embora especificamente seja possível perceber, nesse aglomerado de fatores, que o menos importante dos fatores favorecedores "equipes qualificadas (funcionários e técnicos)" se destaque daqueles colocados do segundo ao sétimo lugares.

Figura 1: Intervalos de confiança para a pontuação média populacional dos fatores favorecedores, referidos à escala de pontuação de 0 a 10 - Professores PROFESSORES - FATORES FAVORECEDORES

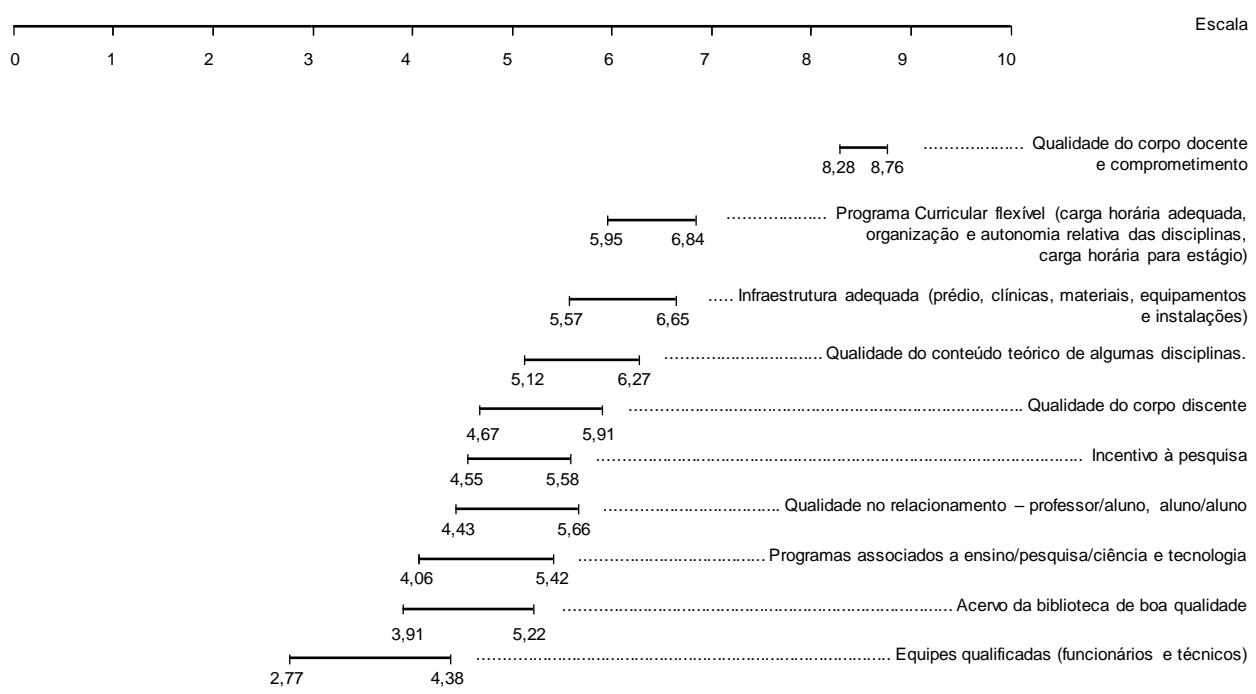

Fonte: Medina (2014).

Dos fatores comprometedores, segundo a avaliação dos docentes, o fator "falta de componentes tais como: competência, motivação, assiduidade, comprometimento e comportamento democrático, por parte de alguns professores" classificou-se em primeiro lugar quanto à sua importância 
(Gráfico 2). A pontuação média alcançada na amostra de professores foi de 7,6 pontos por professor.

A importância dada a esse fator pelo grupo dos professores mostrou-se diferenciada, com significância estatística $(p<0,05)$ das pontuações médias dos fatores colocados nas sete últimas posições do elenco. O mesmo comportamento pode ser constatado para o fator posicionado em segundo lugar na amostra de docentes: "falta de integração e interdisciplinaridade entre as disciplinas".

Ligeiramente diferenciado dos dois primeiros, o fator comprometedor avaliado como o terceiro em importância "programas curriculares tradicionais, antigos e deficientes", embora não difira com significância estatística do quarto e do quinto colocados, se junta aos dois primeiros colocados para formar um conjunto de fatores aos quais os docentes dão importância assemelhada como fatores comprometedores. A Figura 2 evidencia o bloco dos fatores dos três primeiros lugares como diferenciados em importância dos outros sete fatores.

Figura 2: Intervalos de confiança para a pontuação média populacional dos fatores comprometedores, referidos à escala de pontuação de 0 a 10 - Professores

PROFESSORES - FATORES COMPROMETEDORES

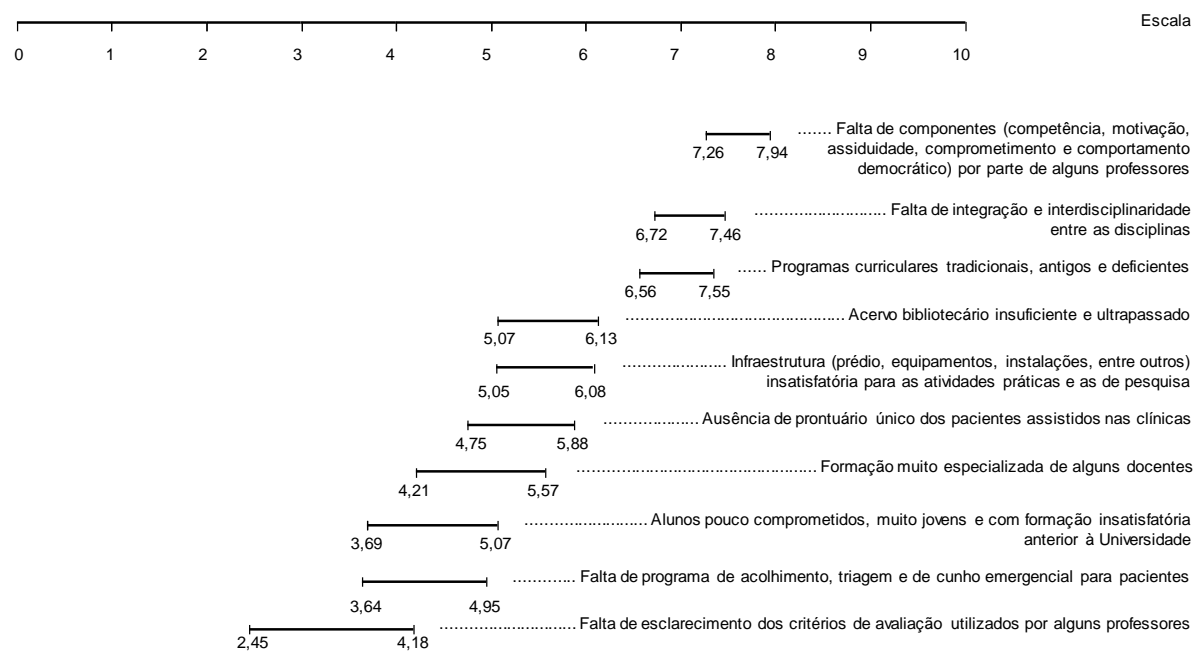

Fonte: Medina (2014). 
A avaliação discente dos fatores favorecedores também os classificou em ordem de importância segundo o total de pontos na amostra de alunos que responderam à convocação da pesquisa. O mais importante, segundo eles e em concordância com os professores, foi o fator "qualidade do corpo docente e comprometimento" (Gráfico 1), que obteve a pontuação média de 7,3. A importância dada a esse fator pelos alunos mostrou-se diferenciada, com significância estatística $(p<0,05)$ das pontuações médias de todos os outros oito fatores favorecedores indicados na pesquisa e classificados por eles do terceiro ao décimo lugares.

Esse principal fator favorecedor para os alunos junta-se ao fator colocado em segundo lugar na amostra "infraestrutura adequada (prédio, clínicas, materiais, equipamentos e instalações)" como de importância estatisticamente equivalente. Esse fator favorecedor do segundo lugar, no entanto, funciona como um elo entre o fator melhor avaliado e os fatores do terceiro ao décimo lugares, como pode ser constatado pela visualização da Figura 3.

A inferência da importância para a totalidade dos alunos do fator favorecedor por eles considerado o mais importante de todos, no intervalo de confiança, permite concluir que a pontuação média populacional desse fator, com $95 \%$ de confiança, se situa entre 6,80 e 7,73.

O fato desse fator se destacar em importância de todos os demais fatores do terceiro ao décimo lugares é confirmado pela avaliação da Figura 3 , na qual se pode verificar que o seu intervalo de confiança se encontra mais à direita na escala de pontuação e não apresenta qualquer interseção com os intervalos de confiança daqueles oito últimos fatores. Percebe-se na análise da Figura 3 que todos os fatores do terceiro ao décimo lugares se aglutinam de modo que, em termos da população discente eles formam um bloco de fatores menos importantes do que o do primeiro lugar, sem distinção global entre eles. 
Figura 3: Intervalos de confiança para a pontuação média populacional dos fatores favorecedores, referidos à escala de pontuação de 0 a 10 - Alunos

ALUNOS - FATORES FAVORECEDORES

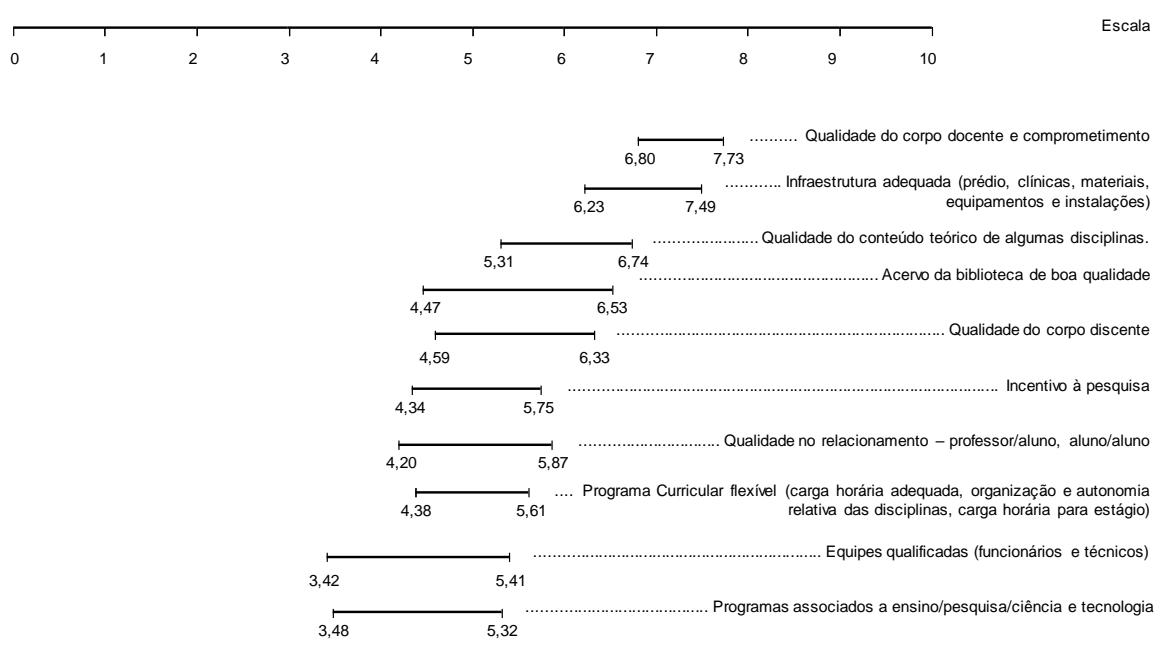

Fonte: Medina (2014).

Dos fatores comprometedores, segundo a avaliação dos alunos, o fator "falta de componentes tais como: competência, motivação, assiduidade, comprometimento e comportamento democrático, por parte de alguns professores" classificou-se, do mesmo modo que fizeram os professores, em primeiro lugar quanto à sua importância (Gráfico 2), alcançando 7,2 de pontuação média na amostra de alunos. A importância dada a esse fator pelo grupo dos alunos mostrou-se diferenciada, com significância estatística $(\mathrm{p}<0,05)$, das pontuações médias dos fatores colocados nas sete últimas posições do elenco.

Comportamento semelhante, exceto pela equivalência ao quarto colocado, pode ser constatado para o fator posicionado em segundo lugar na amostra de discentes: "falta de integração e interdisciplinaridade entre as disciplinas".

A Figura 4 evidencia o fator do primeiro lugar diferenciado do bloco de fatores posicionados a partir do quarto lugar, o que revela uma aglomeração 
única, embora relativamente tênue, dos fatores comprometedores sob o ponto de vista dos alunos.

Figura 4: Intervalos de confiança para a pontuação média populacional dos fatores comprometedores, referidos à escala de pontuação de 0 a 10 - Alunos

ALUNOS - FATORES COMPROMETEDORES

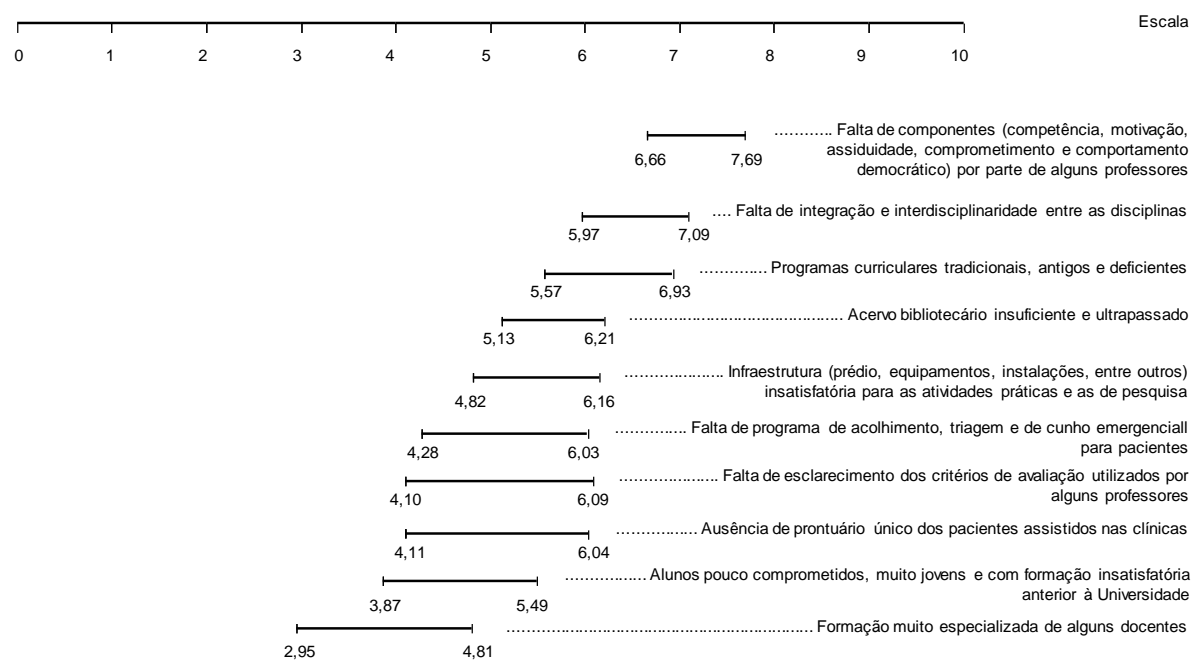

Fonte: Medina ( 2014)

Tendo como base a análise estatística dos dados, observa-se que para os docentes, o principal fator favorecedor é a "qualidade do corpo docente e comprometimento" e os principais fatores comprometedores são, em mesma ordem de importância, "falta de componentes tais como: competência, motivação, assiduidade, comprometimento e comportamento democrático, por parte de alguns professores", "falta de integração e interdisciplinaridade entre as disciplinas" e "programas curriculares tradicionais, antigos e deficientes". Todos esses fatores podem compor o foco de um movimento de ações de melhoria: o fator favorecedor a ser aproveitado como força propulsora e os fatores comprometedores como motivação para ações de melhoria.

A posição dos discentes é assemelhada a dos professores: ressalta a importância do mesmo fator favorecedor "qualidade do corpo docente e 
comprometimento“, embora de modo não hegemônico como para os docentes e concordam com eles no quesito dos fatores comprometedores quando indicam "falta de componentes tais como: competência, motivação, assiduidade, comprometimento e comportamento democrático, por parte de alguns professores" como o mais importante.

No intuito de se ampliar o olhar a respeito dos resultados auferidos, fez-se uma análise dos mesmos, comparando-os com as questões mais discutidas pelos pensadores.

Para as DCN a posição do professor é facilitar e mediar o processo ensino-aprendizagem. Nesta direção, entende Fischer (2009, p. 314) que "o ato pedagógico que envolve discussão e participação dos envolvidos constitui, sem sombra de dúvida, uma das garantias do sucesso na construção do conhecimento". O papel do professor é extremamente importante, uma vez que a formação do aluno não pode ser somente técnica, não apenas voltada à parte científica, terá que ser acompanhada de informações sobre ética e humanismo, na realidade o que se deve buscar é formar um cidadão. Pode-se também dizer que o papel do professor é contribuir com o aluno no seu processo de consciência política, social, profissional (FEUERWERKER, 2003; BEZERRA, 2011).

Para Lazzarin; Nakama; Júnior (2007) ao docente é imperioso estender o campo de reflexão do conceito ampliado de saúde, para os principais problemas de saúde pública do país, para o trabalho integrado e multidisciplinar, indo um pouco além dos aspectos técnicos da profissão.

Moraes (2012), Foresti (2001) e Finkler (2009) entendem que o professor é um modelo de referência a ser seguido pelos estudantes, de habilidade técnica, postura ética, ponte entre o conhecimento disponível e as estruturas cognitivas, culturais e afetivas dos alunos, como também enquanto um exemplo de conduta.

Delors et al. (1996) concebe que melhorar a qualidade da Educação significa, antes de tudo, aperfeiçoar o recrutamento, a formação, o estatuto social e as condições de trabalho dos professores, uma vez que os mesmos 
responderão ao que deles se espera se possuírem os conhecimentos e as competências, as qualidades pessoais, as possibilidades profissionais e a motivação requerida.

A pesquisa ora apresentada deixa claro que os aspectos relativos ao corpo docente tiveram um destaque em importância na qualidade do ensino, especialmente na condição de favorecedor, porém aparece também de forma relevante como comprometedor, ainda que se refira apenas a alguns professores.

Percebe-se que a mudança objetivada, está em grande parte nas mãos dos docentes, o que sugere a necessidade de uma reorientação da prática dos mesmos na busca de novos caminhos que superem alguns dos problemas e desafios profissionais e pessoais, apontados na pesquisa e na literatura consultada.

A relevância do currículo para responder a um ensino de qualidade, constituiu-se em um fator inibidor para os alunos e professores, traduzido na falta de integração e interdisciplinaridade entre as disciplinas. Esta realidade também é constatada em outros estudos como o de Cordioli (2006), e Haddad et al. (2006) que encontraram como resultado a falta de integração e interdisciplinaridade nas estruturas curriculares de outros cursos. Para Morita et al. (2007), estes são aspectos que impedem que os cursos alcancem a competência Atenção à Saúde, como definida nas DCN, prevalecendo uma assistência estanque e sem continuidade.

Zilbovicius (2007), diz que a fragmentação do conhecimento que se reflete na estrutura dos currículos de Odontologia não promove a integração dos conteúdos, gerando uma prática também fragmentada que estimula o conceito biologicista e unicausal da clínica odontológica. É um tipo de prática na qual o saber clínico exclui as dimensões do social e do subjetivo.

Quanto aos programas curriculares tradicionais, antigos e deficientes, no foco das DCN, o conteúdo deve deixar de ser o objetivo principal e passar a ser o meio pelo qual os alunos desenvolvem suas habilidades e adquirem suas competências. O que não significa a perda de importância dos 
conteúdos disciplinares tradicionais na formação, mas dar um passo mais além, servindo-se dos conteúdos para atuar de maneira consciente, crítica, reflexiva e eficaz diante da diversidade de problemas da realidade. Pode-se constatar isso na fala de Antunes, ao entender que é mais importante saber lidar com a informação, do que retê-la e fazer dela "um caminho para solucionar problemas; aprender não é estocar informações, mas transformarse, reestruturando passo a passo o sistema de compreensão do mundo" (ANTUNES, 2004, p. 22). Deste ponto de vista, a seleção, a sequência, bem como a forma de trabalhar os conteúdos adquire um novo enfoque diferente do tradicional, que pressupõe mudanças no desenho curricular e no processo ensino-aprendizagem.

A pesquisa realizada, mostra que o curso de Odontologia da UFF acompanha o resultado dos autores citados no corpo do artigo, estando, ainda, em desacordo com a qualidade pretendida nas DCN.

\section{Conclusão}

O objetivo da pesquisa foi identificar os fatores favorecedores e os comprometedores da qualidade do ensino do curso de graduação em Odontologia da Universidade Federal Fluminense. Com base nos resultados apresentados no estudo, observou-se que:

Os fatores favorecedores, na opinião de alunos e professores, foram: Infraestrutura adequada; Qualidade do corpo docente e comprometimento; Acervo da biblioteca de boa qualidade; Qualidade do corpo discente; Programas associados a ensino/pesquisa/ciência e tecnologia; Programa curricular flexível; Incentivo à pesquisa; Qualidade no relacionamento professor/aluno, aluno/aluno; Equipes qualificadas (funcionários e técnicos) e Qualidade do conteúdo teórico de algumas disciplinas.

Os fatores comprometedores foram: Infraestrutura insatisfatória para as atividades práticas e as de pesquisa; Falta de componentes tais como: competência, motivação, assiduidade, comprometimento e comportamento democrático, por parte de alguns professores; Programas curriculares 
tradicionais, antigos e deficientes; Falta de integração e interdisciplinaridade entre as disciplinas; Acervo bibliotecário insuficiente e ultrapassado; Ausência de prontuário único dos pacientes assistidos nas clínicas; Falta de esclarecimento dos critérios de avaliação utilizados por alguns professores; Falta de programa de acolhimento, triagem e de cunho emergencial para pacientes; Alunos pouco comprometidos, muito jovens e com formação insatisfatória anterior à Universidade e Formação muito especializada de alguns docentes.

Para os docentes, o principal fator favorecedor foi a "Qualidade do corpo docente e comprometimento”, o qual se diferencia estatisticamente ao nível de 5\% de significância de todos os demais fatores favorecedores.

A posição dos discentes é assemelhada à dos professores: ressaltam a importância do mesmo fator favorecedor "Qualidade do corpo docente e comprometimento“, embora de modo não hegemônico como para os docentes. Para os alunos o referido fator não é diferente estatisticamente do fator "Infraestrutura adequada", mas apresenta diferença estatisticamente significativa dos todos os outros fatores favorecedores ao nível de 5\%.

Para os professores os principais fatores comprometedores, em mesma ordem de importância obtida na pesquisa, são - "Falta de componentes tais como: competência, motivação, assiduidade, comprometimento e comportamento democrático, por parte de alguns professores", "Falta de integração e interdisciplinaridade entre as disciplinas" e "Programas curriculares tradicionais, antigos e deficientes", não sendo estatisticamente diferentes entre si ao nível de 5\% de significância, porém esses três fatores são estatisticamente diferentes $(p<0,05)$ dos demais fatores comprometedores.

Os alunos concordam com os professores a respeito dos fatores comprometedores ao indicarem a "Falta de componentes tais como: competência, motivação, assiduidade, comprometimento e comportamento democrático, por parte de alguns professores" como o mais importante, sendo que esse fator mostrou-se diferenciado, com significância estatística 
$(\mathrm{p}<0,05)$, dos sete últimos fatores comprometedores por eles hierarquizados da maior para a menor importância. No entanto, esse fator não se mostrou estatisticamente diferente dos fatores "Falta de integração e interdisciplinaridade entre as disciplinas" e "Programas curriculares tradicionais, antigos e deficientes" ao nível de 5\% de significância.

Como foi visto foram inúmeros os desafios apresentados pela pesquisa, em busca da qualidade do ensino de Odontologia, tendo em vista a total implantação das DCN. Acredita-se que o conhecimento da importância das mudanças na Saúde e na Educação, por parte dos envolvidos, poderão contribuir para a qualidade de vida na sociedade brasileira. Para que tal mudança possa ocorrer é preciso ter em mente, que este empreendimento deverá contar com o esforço conjunto e a responsabilidade de toda a comunidade universitária: discentes, docentes, gestores, entre outros.

Espera-se conseguir com esta pesquisa propiciar novos caminhos para uma formação de melhor qualidade e mais adequada aos tempos e exigências atuais, sobretudo para aqueles que enfrentam essa realidade e para a sociedade em geral.

\section{Referências}

ANTUNES, C. Como desenvolver as competências em sala de aula. Petrópolis: Vozes, 2004.

BARDIN, L. Análise de conteúdo. Lisboa: Edições 70, 1977.

BERTOLIN, J. C. G.; MARCHI, A. C. B. de. Uma proposta de indicadores para avaliar a qualidade de disciplinas semipresenciais em cursos de graduação. Revista Brasileira de Computação Aplicada, Passo Fundo, v.1, n. 1, p. 30-41, set. 2009.

BEZERRA, T. O. C. A política de cotas em universidades e inclusão social: desempenho de alunos cotistas e sua aceitação no grupo acadêmico. 187 f. 2011. Tese (Doutorado em Educação) - Universidad de la Empresa, Montevidéu-Uruguai, 2011.

BRASIL. Ministério da Educação. Conselho Nacional de Educação/Câmara de Educação Superior. Parecer CNE/CES 1.300/2001 - HOMOLOGADO. Despacho do ministro em 4/12/2001. Aprova as Diretrizes Curriculares Nacionais dos Cursos de Graduação de Farmácia e Odontologia. Diário Oficial da União, Brasília, DF, 07 dez. 2001. 
Ministério da Educação. Conselho Nacional de Educação/Câmara de Educação Superior. Resolução CNE/CES n.3 de 19 de Fevereiro de 2002. Institui as Diretrizes Curriculares Nacionais do Curso de Graduação em Odontologia. Diário Oficial da União, Brasília, DF, 04 mar. 2002.

CORDIOLI, O. F. G. O processo de formação do cirurgião-dentista e a prática generalista da Odontologia: uma análise a partir da vivência profissional. 2006. 117 f. Dissertação. (Programa de Pós-graduação Ensino em Ciências da Saúde) Universidade Federal de São Paulo. Escola Paulista de Medicina, São Paulo. 2006.

DELORS, J. et al. Educação: um tesouro a descobrir: Relatório para a UNESCO da Comissão Internacional sobre Educação para o Século XXI. Rio Tinto, Portugal: Ed. Asa, 1996.

FEUERWERKER, L. C. M. Educação dos profissionais de saúde hoje: problemas, desafios, perspectivas e as propostas do Ministério da Saúde. Revista da ABENO, Brasília, DF, v. 3, n. 1, p. 24-27, jan./dez. 2003.

FISCHER, B. T. D. Docência no ensino superior: questões e alternativas. Educação, Porto Alegre, v. 32, n. 3, p. 311-315, set./dez. 2009.

FINKLER, M. Formação ética na graduação em odontologia: realidades e desafios. 2009. 259 f. Tese (Doutorado em Odontologia) - Programa de Pós-graduação em Odontologia, Universidade Federal de Santa Catarina, Florianópolis. 2009.

FORESTI, M. C. P. P. Ação docente e desenvolvimento curricular: aproximações do tema. Revista da ABENO, Brasília, DF, v. 1, n. 1, p. 13-16. 2001.

HADDAD, A. E.; LAGANÁ, D. C.; ASSIS, E. Q. et al. A aderência dos cursos de graduação em odontologia às diretrizes curriculares nacionais. In: BRASIL. Ministério da Saúde; BRASIL.Ministério da Educação. A aderência dos cursos de graduação em enfermagem, medicina e odontologia às diretrizes curriculares nacionais. Série F. Comunicação e Educação em Saúde. Brasília, Ministério da Saúde, 2006. p. 119-152.

LAZZARIN; NAKAMA, L.; CORDONI JÚNIOR, L. O papel do professor na percepção dos alunos de odontologia. Saúde e Sociedade, São Paulo, v. 16, n. 1, p. 90-101, jan/abr. 2007.

LIBÂNEO, J. C. Organização e gestão da escola: teoria e prática. Goiânia: Editora Alternativa, 2004.

MALHOTRA, N. K. Pesquisa de marketing: uma orientação aplicada. Porto Alegre: Bookman, 2004.

MASETTO, M. T. Competência pedagógica do professor universitário. São Paulo: Summus, 2003. 
MATTAR, F. N. Pesquisa de marketing: metodologia, planejamento. São Paulo: Atlas, 2005.

MATOS, M. S.; TENÓRIO, R. M. A avaliação como instrumento de aperfeiçoamento do ensino em odontologia. In: LORDÊLO, J. A. C.; DAZZANI, M. V. (Org.). Avaliação educacional: desatando e reatando nós. [online]. Salvador: EDUFBA, 2009. p. 123-153. ISBN 978-85-232-0654-3. Disponível em: $<$ http://books.scielo.org>.

MEDINA, P. F. O ensino de Odontologia: fatores favorecedores e comprometedores na qualidade acadêmica. 196 f. 2014. Tese (Doutorado em Educação) - Universidad de la Empresa, Montevidéu-Uruguai, 2014.

MORAES, R. C. M. Da oralidade à humanidade: a temática da humanização do ensino odontológico na Universidade Federal Fluminense. 174 f. 2012. Tese (Doutorado em Educação) - Universidad de la Empresa, Montevidéu, Uruguai, 2012.

MORITA, M. C. et al. Implantação das Diretrizes Curriculares Nacionais em Odontologia. Maringá: Dental Press: ABENO: OPAS: MS. 2007.

PEREZ LINDO, A. Nuevos paradigmas y cambios en la conciencia histórica. Buenos Aires, Eudeba, 1998.

PIMENTA, S. G.; ANASTASIOU, L. G. C.; CAVALLET, V. J. Docência no ensino superior. In: BARBOSA, R. L. L. (Org.). Formação de educadores: desafios e perspectivas. São Paulo: Editora UNESP, 2003. p. 267-278.

REIS, S. M. A. S. et al. Formação odontológica: persiste o descompasso entre o perfil do cirurgião-dentista atualmente formado e as demandas da sociedade por saúde bucal. Revista de Educação Popular, Uberlândia, v. 8, p. 86-97, jan./dez. 2009.

SAMPIERI, R. H.; COLLADO, C. F.; LUCIO, P. B. Metodologia da pesquisa. São Paulo: McGraw-Hill, 2006

SECCO, L. G.; PEREIRA M. L. T. Concepções de qualidade de ensino dos coordenadores de graduação: uma análise dos cursos de odontologia do Estado de São Paulo. Interface: comunicação, saúde, educação, Botucatú, v. 8, n. 15, p. 313-30, mar./ago. 2004.

ZILBOVICIUS, C. Implantação das diretrizes curriculares para cursos de graduação em odontologia no Brasil: contradições e perspectivas. 2007. $211 \mathrm{f}$. Tese (Doutorado em Ciências Odontológicas) - Faculdade de Odontologia da Universidade de São Paulo, São Paulo. 2007. 